\title{
Sexual dimorphism in size of the skull of Spanish ibex Capra pyrenaica
}

\author{
Paulino FANDOS and Carlos R. VIGAL
}

Fandos P. and Vigal C. R. 1993. Sexual dimorphism in size of the skull of Spanish ibex Capra pyrenaica. Acta theriol. 38: 103 - 111.

Sexual dimorphism in the skull of Spanish ibex Capra pyrenaica Schinz, 1838 is analyzed by means of univariate and multivariate techniques in one of the most representative populations of the species, located in the Sierra de Gredos, central Spain. Thirty eight measurements were used for the analysis: 30 of the skull and mandible, and 8 of the horn. Eighty three skulls (40 males and 43 females) of individuals older than 4 years were used. In 36 out of the 38 variables males were significantly larger than females. Horn characters showed the highest variability and also the most significant differences between sexes. Values of Mahalanobis distance between males and females were high $\left(D^{2}=323.1\right)$. When Factor Analysis is performed with the whole set of 38 variables, 7 Principal Factors were extracted, scores of Principal Factor 2 (related with horn variables) and Principal Factor 3 (related to molar toothrow length) showing significant differences between sexes. In this analysis, horn characters (Principal Factor 2) accumulate the sexual dimorphism of other skull traits. However, if the same analysis is performed without horn characters, 5 Principal Factors were extracted, scores of three Principal Factors showing significant differences between sexes. Highest sexual dimorphism in this analysis corresponds to the Principal Factor 3 (molar toothrow), follow the Principal Factor 2 (posterior region of the skull) and Principal Factor 1 (main length measurements). This suggest that the high degree of sexual dimorphism observed in the Spanish ibex skull is mainly related to horn traits and, to a lesser extent, of other skull features like molar toothrow length.

Museo Nacional de Ciencias Naturales, c/ José Gutierrez Abascal 2, 28006 Madrid, Spain (PF); Instituto Conservacion de la Naturaleza, c/ Costanilla de San Lázaro 3, Toledo, Spain (CRV)

Key words: Capra pyrenaica, craniometry, sexual dimorphism, Spain

\section{Introduction}

Sexual dimorphism has been described in the majority of vertebrates (Selander 1972, Clutton-Brock et al. 1977). Takes its maximum level in ungulates, mainly in cervids (Clutton-Brock et al. 1980) and bovides (Geist 1966), that have been characterised by the development of heavy skulls and large horns that are mainly used to give and receive strong strokes in intrasexual fights. Horns are considered sexually dependent traits. In the Caprini tribe, horns have been studied according to their evolutive meaning (Geist 1966), their importance in the fight, their shape and silhouette originated from the different types of fight (Schaffer 1968, Schaffer 
and Reed 1972, Kitchener 1985, 1988), points of incidence (Alvarez 1990), age, nourishment (Fandos 1991).

The Spanish ibex Capra pyrenaica Schinz, 1838 is characterised by the presence of horns in both sexes. In this species, horns show a high degree of sexual dimorphism, both in thickness and in length and shape, these traits being up to ten times larger in males than in females (Fandos et al. 1989).

Nevertheless, only a few studies reflect the consequences that horns produce on the skull morphology, due to the different use that both sexes made of them. Only Jaslow (1989) deals with the complexity of the sutures in both sexes in Ovis orientalis.

The aim of this study was to describe and analyze sexual dimorphism in different parts of the Spanish ibex skull, and to answer the question of whether horns could account for the majority of the intersexual variation or not.

\section{Material and methods}

\section{Material}

The study is based on 83 skulls ( 40 males and 43 females) that have been collected from 1983 to 1985 in Gredos (Avila). This material belongs to the collection of the "Unidad de Zoología Aplicada" Madrid. All the specimens were of known sex and age. Age was determined using horn segments, and cementum lines (Fandos 1991, Fandos et al., in press).

\section{Variables}

Up to 38 measurements were used in the analysis, 30 related with the skull and mandible and 8 with the horns (Fig. 1). Measurements follow the nomenclature used by others authors (Couturier 1962, Pfeffer 1967, Schaffer and Reed 1972, Driesch 1976, Lochman and Bendova 1978, GarcíaGonzález 1980, Hrabe and Koubık 1983, Fandos and Vigal 1988). The complete list of variables is given in the Table 1.

Measurements were taken with a caliper except frontal length curve (29. LFC) and parietal length (30. LP) that were taken with a tape. Only adult specimens older than 4 years have been used, because at this age they reach the asymptotic values in most of the variables (Fandos and Vigal 1988).

\section{Statistical analysis}

Basic statistics and analysis of variance (ANOVA) between both sexes was calculated for every variable by the computer program BMDP7D (Dixon 1987). A multivariate statistic, based on Mahalanobis' distance $\left(D^{2}\right)$ was calculated by BMDP3D, which considers differences in means, variances, and covariances of characters among groups (Wiig and Andersen 1986).

Stepwise discriminant analysis was performed using BMDP7M with two objectives. First, to show the contribution of each variable the discriminant function that separate the sexes and shows the importance of each one. Second, to provide a function with a short number of variables for the classification of the specimen in its proper sex (Marcus 1990).

In order to determine the skull features that indicate trends in the differences between sexes, two complementary Principal Factor Analysis (PFA) using correlation matrixes (Pimentel 1979, Marcus 1990) have been performed; one with all the variables and the other one removing the variables related with the horns.

Only those factors that add up to explain at least $95 \%$ of the total variance have been examined. The factors have undergone an orthogonal rotation (Neff and Marcus 1980). 

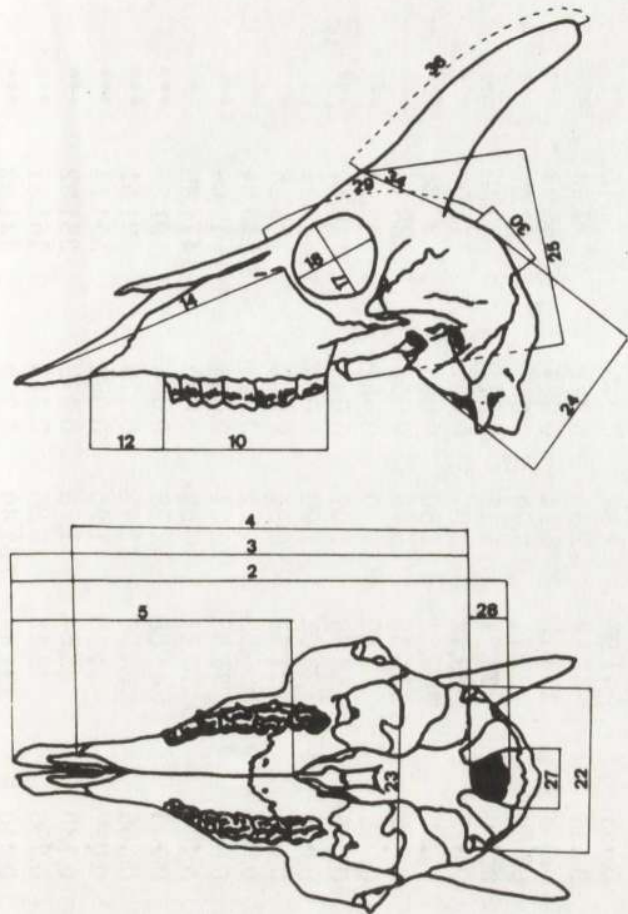
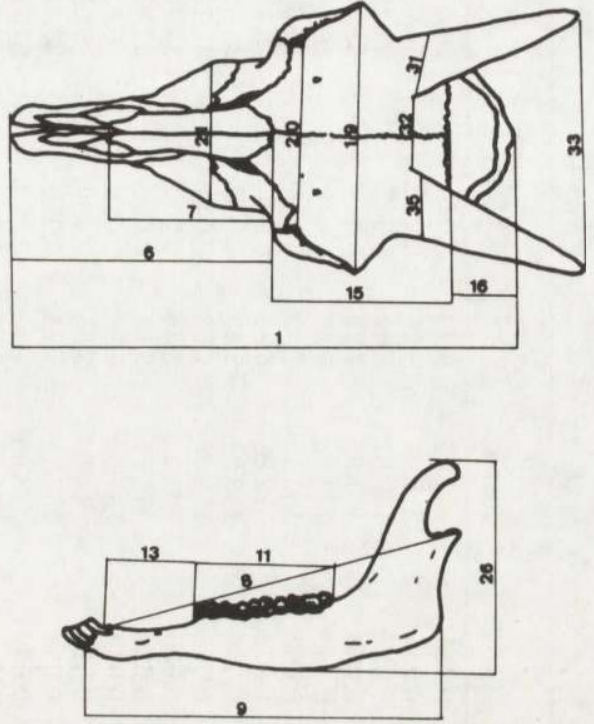

Fig. 1. Cranial dimensions of Spanish ibex, used in this study. Numbers indicate measurements listed in the Table 1.

\section{Results}

There is a high degree of sexual dimorphism in the skull of the Spanish ibex, 36 out of 38 variables showing significant differences (Table 1). Males are larger than females, except AMC which is significantly larger in females (Table 1). In general, variability is higher in males $(\mathrm{CV}=0.081)$ than in females $(\mathrm{CV}=0.067)$. Nevertheless, the variability of skull traits is similar in both sexes, ranging around 0.05 of $\mathrm{CV}$. The highest variability, between 0.10 and 0.20 of $\mathrm{CV}$, and also the main differences between males and females are found in horn characters (Table 1).

The multivariate separation between sexes was highly significant (Mahalanobis $D^{2}=323.09$, Hotteling $T^{2}=4517.62, F=37.42, \mathrm{df}=38,17, p<0.001$ ).

The discriminant analysis indicates that variables related with horns show a higher contribution to the differences betwe n sexes, with values of the $F$ statistic very much larger than the rest (Table 1). This analysis determines a Discriminant Function (DF) with five variables:

$$
\mathrm{DF}=-\mathrm{LP}(0.62)-\mathrm{AZ}(0.76)-\mathrm{AMCD}(1.02)+\mathrm{DFM}(1.28)+\mathrm{DLM}(1.33)+5.59
$$




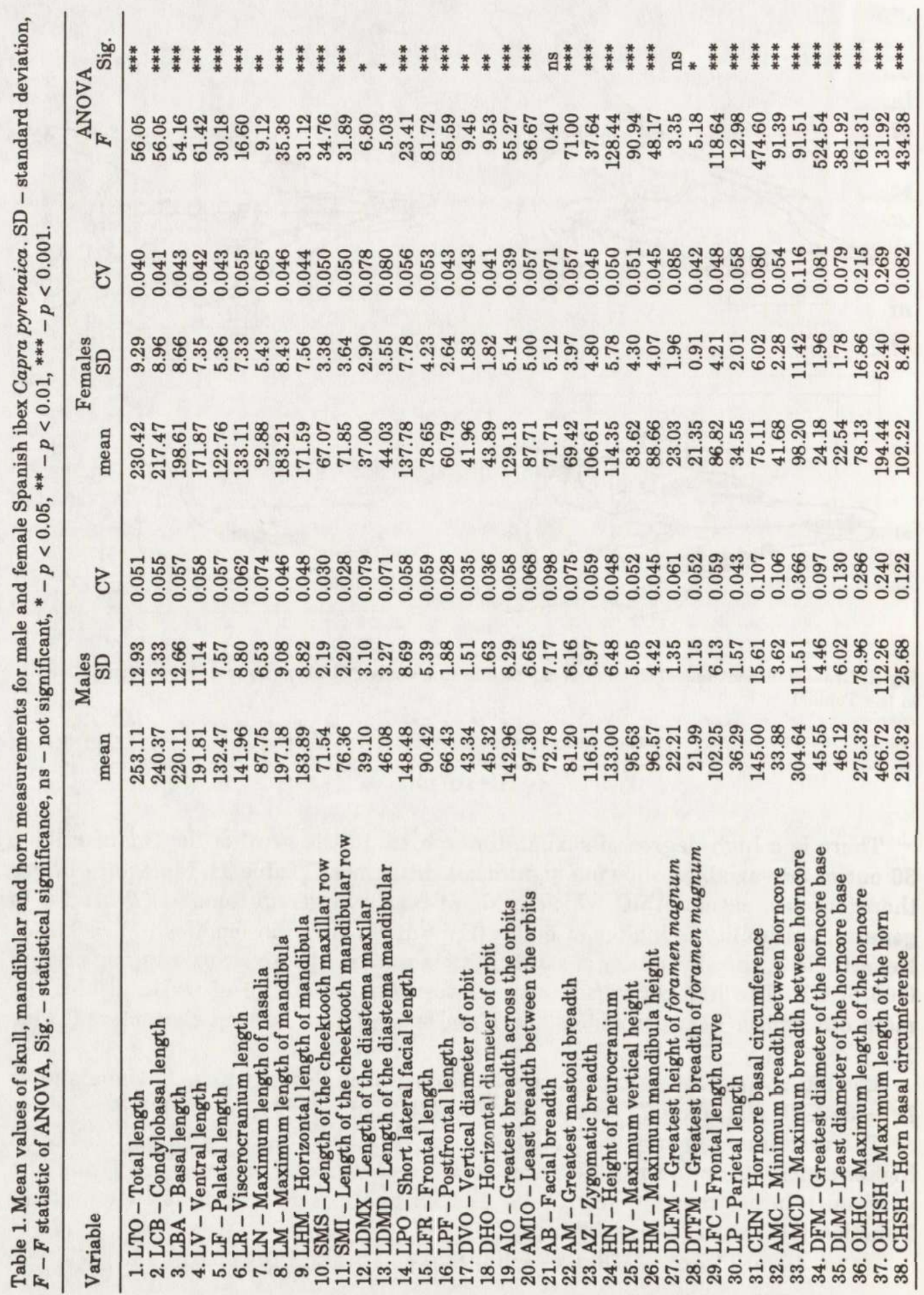


Fig. 2. Histogram of canonical score of male (x $=2.6)$ and female $(x=-2.8)$ Spanish ibex, based on 38 cranial dimensions.

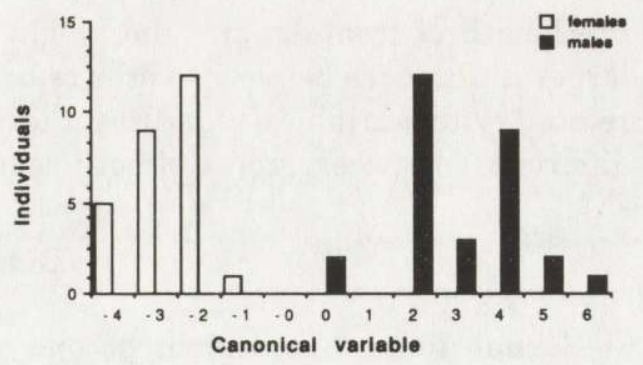

This function separates skulls of males and females with $100 \%$ reliability, as showed in the histogram (Fig. 2) of the discriminat function.

In the first factor analysis (FA), when all the variables are used, it is necessary to extract 7 factors to explain $95 \%$ of the variance (Table 2 ). The first two principal factors (PF) account for more than $75 \%$ of the variance. The scores of PF1, represented mainly by length dimensions, do not show significant differences between both sexes $(F=2.78, \mathrm{df}=1,54, p>0.05)$. The variables related with the horns are grouped in the PF2. This factor shows significant differences between sexes $(F=117.37, \mathrm{df}=1,54, p<0.001)$.

In a second analysis, where the influence of horns is eliminated by using only skull and mandible variables, 5 factors were extracted, accounting for more than $95 \%$ of the explained variance (Table 2). The PF1 represents the variability of the length dimensions of skull. Scores of PF1 and it show significant differences between males and females $(F=6.02, \mathrm{df}=1,54, p=0.017)$. The PF2, related with

Table 2. Principal factors (PF) extracted in the two analysis of sexual dimorphism and variables with loadings $>0.55$ with each factor. $\mathrm{VE}$ - percentage of variance explained, Sig. - significance of the differences between sexes (ANOVA).

\begin{tabular}{lcll}
\hline PF & VE & Sig. & \multicolumn{1}{l}{ Variables includes in the factors } \\
\hline & & & \multicolumn{1}{c}{ Whole set of variables } \\
PF1 & 42.38 & ns & Main length (1 to 9) and breadth (19 to 23) \\
PF2 & 35.40 & $* * *$ & Horn variables (31 to 38), and LFR, LFC, HV and HN \\
PF3 & 8.24 & $* *$ & Molar series (SMS, SMI) \\
PF4 & 3.93 & ns & Post frontal and parietal LP, LPF \\
PF5 & 3.54 & ns & Foramen magnum DTFM \\
PF6 & 1.70 & ns & Orbits (DHO, DVO) \\
PF7 & 1.61 & ns & - \\
& & & \\
& & & Reduced set of variables \\
PF1 & 53.63 & $*$ & Main length (1 to 9) and breadth (19 to 23) \\
PF2 & 18.98 & $* *$ & Frontal length (LFR, LFC, HV) \\
PF3 & 11.40 & $* * *$ & Molar series (SMS, SMI) \\
PF4 & 5.99 & ns & Foramen magnum - DTFM \\
PF5 & 5.25 & ns & Post frontal and parietal (LP, LPF) \\
\hline
\end{tabular}


the length of frontals, and the height of neurocranium, is the one which shows larger differences between scores of both sexes $(F=33.91, p<0.001)$. The PF3 is related with variables regarding the molar series and it also shows significant differences between scores of both sexes $(F=14.30, p<0.001)$.

\section{Discussion}

Sexual dimorphism might be one of the morphological features related with ecological and behaviour adaptation in mammals (Ralls 1977). In ungulates, the use of horns for fights implies a marked distinction of both sexes. So that, only in few cases (Jaslow 1989) it has gone in as deep dimorphism of other cranial structures as in carnivores (Ewer 1973). Most of the studies about sexual dimorphism, associate it with the type of reproduction (Clutton-Brock et al. 1980, Jarman 1983), habitat (Geist and Bayer 1988), type of fight (Schaffer and Reed 1972), and its evolutive significance (Schaffer 1968, Janis 1982).

The Spanish ibex could be one of the species of the genus Capra with a higher sexual dimorphism (Fandos et al. 1991). In bovides, different species of the genus Ovis can be highlighted as the species with larger sexual dimorphism (Pfeffer 1967, Geist 1971, Schaller 1977). This high degree of sexual dimorphism is associated with the presence of horns, because all the variables related with horns show higher dimorphism, with values up to two times higher in males than in females, except the minimum breadth between horns (AMC) which is larger in females, probably because in the skull of males the growth of horn core causes the minimum breadth to decrease.

The coefficient of variation is generally higher in males than in females. The horns show higher coefficients than other skull dimensions, coming over $30 \%$ (CV $=0.36$ ), that could be related with a continued growth of horns (Fandos and Vigal 1988). Other variables with a high coefficient of variation either in males or in females are the nasals, the mandibular and maxilar diastemas or mastoidal breadths. High coefficient of variation in these variables were found in other ungulates as Roe deer Capreolus capreolus (Kratochvíl 1984) and chamois Rupicapra rupicapra (Hrabě and Koubek 1983).

In the first principal factor analysis (PFA), performed with all the variables, the principal factor 2 (PF2), which groups all the variables of horns, masks the differences between sexes in other parts of the skull. The horns are the elements that show the highest differences between sexes. This is logical from a perspective in which the sex and the type of sexual selection have influenced the size and shape of horns, considered as secondary sexual traits. The influence of sexual behaviour in sexual dimorphism due to the strong polygamy has been proved in the genus Capra (Schaffer 1968, Schaffer and Reed 1972), as well as in the Capra pyrenaica species itself (Alvarez 1990). In ungulates, with a higher tendency towards monogamy, sexual differences in the skull dimensions are less marked (Jarman 1983, Georgiadis 1985). 
In the second PFA, without the horn variables, scores of principal factors 1,2 and 3, show significant differences between sexes, being highly significant in PF2 and $3(\mathrm{~F}>14.3, p<0.001)$. The PF1 represents the variability of the skull length dimensions.

The PF2, that represents the variability of the medium-posterior area of skull, is directly related with horns. The medium-posterior region of skull includes frontal bones, where horns are formed and supported. Frontal bones also function together, with parietals and occipitals, as the point of insertion of the muscles that support the bumps in skull (Schaffer 1968, Schaffer and Reed 1972). However, from an evolutionary point of view, there are not many discussions that determine the presence of horns in the females of bovides (Kiltie 1985, Estes 1991) and the large differences in the species in which both sexes have horns (Geist 1966, Janis 1982).

The significant differences between scores of male and female skull in PF3, mainly related with the molar series, may be due to ecological factors as the different interaction of males and females with the environment, or to the competition itself of individuals of different sex for the limitation of resources (Slatkin 1984), or to the different utilization of the food or the type of feeding, although this is not proved (Martínez and Martínez 1986, Martínez 1989).

Acknowledgements: We would like to thank Dr. F. Palacios, L. Cuesta and all the staff colaborators of the UZA for their help in collecting and preparation conservation of the material. We wish to thank also the CSIC for its support to this study.

\section{References}

Alvarez F. 1990. Horns and fighting in male Spanish ibex, Capra pyrenaica. J. Mammal. 71: $608-616$.

Clutton-Brock T. H., Harvey P. H. and Rudder B. 1977. Sexual dimorphism, socionomic sex ratio and body weight in primates. Nature 269: $797-800$.

Clutton-Brock T. H., Albon S. D. and Harvey P. H. 1980. Antlers, body size and breeding systems in the Cervidae. Nature 285: $565-567$.

Couturier M. 1962. Le bouquetin des Alpes. (Capra aegagrus ibex ibex L.) Ed. par l'auteur. Grenoble: $1-1564$.

Dixon W. J. 1987. BMDP Statistical software, 1985. University of California Press, Berkeley: 1 -940.

Driesch A. Von Den. 1976. A guide to the measurement of animal bones from archeological sites. Peabody Museum Bull. 1: 1 - 45 .

Estes R. D. 1991. The significance of horns and other male sexual characters in female bovids. Appl. Anim. Behav. Sci. 29: $403-451$.

Ewer R. F. 1973. The carnivores. Weidenfeld and Nicholson. Cornell University Press, London: 1 494.

Fandos P. and Vigal C. R. 1988. Body weight and horn length in relation to age of the Spanish wild goat. Acta theriol. 33: $239-242$.

Fandos P., Vigal C. R. and Fernández López J. M. 1989. Weigth estimation of Spanish ibex, Capra pyrenaica, and Chamois, Rupicapra rupicapra (Mammalia, Bovidae). Z. Säugetierk. 54: 239 - 242.

Fandos P. 1991. La cabra montés (Capra pyrenaica) en el Parque Natural de las Sierras de Cazorla, Segura y Las Villas. Colección Técnica. ICONA Eds., Madrid: 1 - 176 . 
Fandos P., Orueta J. F. and Aranda Y. 1991. Biometrical introduction to genus Capra. Abstracts, 1st European Congress of Mammalogy, Lisboa: 132 - 133.

Fandos P., Vigal C. R., Machordom A., Fernández J. M., Martínez T. and Palacios F. (in press). Horn segments and dental cementum lines as age criteria for the Spanish wild goat. Säugetierk. Mitt.

Hrabe V. and Koubek P. 1983. Craniometric characteristics of Rupicapra rupicapra caucasica. Folia Zool. 32: $73-84$.

García-González R. 1980. Estudio del crecimiento postnatal en corderos de raza rasa aragonesa, ecotipo antosano. Ph.D. Thesis. Universidad de Barcelona: 1 - 468.

Geist V. 1966. The evolution of horn-like organs. Behaviour 27: 175-214.

Geist V. 1971. Mountain sheep. The University of Chicago Press, Chicago: 1- 383 .

Geist V. and Bayer M. 1988. Sexual dimorphism in the Cervidae and its relation to habitat. J. Zool., Lond. 214: $45-53$.

Georgiadis N. 1985. Growth patterns, sexual dimorphism and reproduction in African ruminants. Afr. J. Ecol. 23: $75-87$.

Janis C. 1982. Evolution of horns in ungulates: ecology and paleoecology. Biol. Rev. 57: 261 - 318.

Jarman P. 1983. Mating systems and sexual dimorphism in large, terrestrial mammalian herbivores. Biol. Rev. 58: $485-520$.

Jaslow C. R. 1989. Sexual dimorphism of cranial suture complexity in wild sheep (Ovis orientalis). Zool. J. Linn. Soc. 95: $273-284$.

Lochman J. and Bendová E. 1978. The main craniometric data on the skulls of mouflon. Lesnictví 24: 435 - 438. [In Czech with English summary]

Kiltie R. 1985. Evolution and function of horns and hornlike organs in female ungulates. Biol. J. Linn. Soc. 24: $299-320$.

Kitchener A. 1985. The effect of behaviour and body weight on the mechanical design of horns. J. Zool., Lond. 205: $191-203$.

Kitchener A. 1988. An analysis of the forces of fighting of the blackbuck (Antilope cervicapra) and the bighorn sheep (Ovis canadensis) and the mechanical design of the horns of bovids. J. Zool., Lond. 214: $1-20$.

Kratochvil Z. 1984. Veränderungen am Gebiss des Rehwildes (Capreolus capreolus L.). Folia Zool. 33: $209-222$.

Marcus L. F. 1990. Traditional morphometrics. [In: Proceedings of the Michigan Morphometrics Workshop. F. J. Rohlf and F. L. Bookstein, eds]. Special Publication No. 2, The University of Michigan, Museum of Zoology. Ann Arbor, Michigan: 77 - 122.

Martínez T. and Martínez E. 1987. Diet of the Spanish wild goat, Capra pyrenaica, in spring and summer at the Sierra de Gredos, Spain. Mammalia 52: 347 - 357.

Martínez T. 1989. Recursos tróficos de la Cabra montés (Capra pyrenaica, Schinz, 1838) en la Sierra de Gredos, durante Otoño e Invierno. Ecología 3: 179 - 186.

Neff N. A. and Marcus L. F. 1980. A survey of multivariate methods for systematics. Privately published, New York: $1-243$.

Pfeffer P. 1967. Le mouflon de Corse (Ovis ammon musimon, Schreber, 1782) position systematique, écologie, et ethologie comparees. Mammalia 31 (supl): $1-262$.

Pimentel R. A. 1979. Morphometrics. The Multivariate Analysis of Biological Data. Kendall and Hunt Publishing Co., Dubuque: $1-276$

Ralls K. 1977. Sexual dimorphism in mammals: avian models and unanswered questions. Am. Nat. 111: 917 - 938 .

Schaffer W. M. 1968. Intraspecific combat and the evolution of the Caprini. Evolution 22: 817-825.

Schaffer W. M. and Reed C. A. 1972. The co-evolution of social behaviour and cranial morphology in sheep and goats (Bovidae, Caprini). Fieldiana (Zool.) 61: 1 - 68.

Schaller G. B. 1977. Mountain Monarchs. Chicago University Press, Chicago: $1-425$.

Selander R. K. 1972. Sexual selection and dimorphism in birds. [In: Sexual selection and the descent of man. B. Campbell, ed]. Aldine, Chicago: $180-230$. 
Slatkin M. 1984. Ecological causes of sexual dimorphism. Evolution 38: $622-630$.

Wiig O. and Andersen T. 1986. Sexual size dimorphism in the skull of Norwegian lynx. Acta theriol. 31: $147-155$.

Received 15 June 1992, accepted 27 January 1993. 